\title{
Collaborative knowledge work environments
}

\author{
Judith H. Heerwagen ${ }^{1}$, Kevin Kampschroer ${ }^{2}$, Kevin M. Powell ${ }^{3}$ and Vivian Loftness ${ }^{4}$ \\ 1J. H. Heerwagen \& Associates, Inc., 2716 NE 91st Street, Seattle, WA 98115, US \\ E-mail: j.heerwagen@att.net \\ ${ }^{2}$ US General Services Administration, Public Buildings Service, 1800 F Street NW, Washington, \\ DC 20405-0002, US \\ E-mail: Kevin.kampschroer@gsa.gov \\ ${ }^{3}$ Charles M. Salter Associates, 130 Sutter Street, San Francisco, CA 94104, US \\ E-mail: kevin.powell@cmsalter.com \\ ${ }^{4}$ Carnegie Mellon University, School of Architecture, Pittsburgh, PA 15213, US \\ E-mail: Loftness@cmu.edu
}

\begin{abstract}
How can the physical design of the workplace enhance collaborations without compromising an individual's productivity? The body of research on the links between physical space and collaboration in knowledge work settings is reviewed. Collaboration is viewed as a system of behaviours that includes both social and solitary work. The social aspects of collaboration are discussed in terms of three dimensions: awareness, brief interaction and collaboration (working together). Current knowledge on the links between space and the social as well as individual aspects of collaborative work is reviewed. The central conflict of collaboration is considered: how to design effectively to provide a balance between the need to interact and the need to work effectively by oneself. The body of literature shows that features and attributes of space can be manipulated to increase awareness, interaction and collaboration. However, doing so frequently has negative impacts on individual work as a result of increases in noise distractions and interruptions to on-going work. The effects are most harmful for individual tasks requiring complex and focused mental work. The negative effects are compounded by a workplace that increasingly suffers from cognitive overload brought on by time stress, increased workload and multitasking.
\end{abstract}

Keywords: cognitive overload, collaboration, evidence-based design, individual effectiveness, interaction, knowledge work, office awareness, workplace awareness, workplace design

Comment la conception physique du lieu de travail peut-elle améliorer les collaborations sans compromettre la productivité individuelle ? L'auteur passe en revue l'ensemble des recherches conduites sur les liens qui existent entre l'espace physique et la collaboration au niveau de la connaissance du cadre de travail. La collaboration est définie comme un système de comportements qui recouvre le travail en groupe et le travail solitaire. Les aspects sociaux de la collaboration sont examinés sous trois angles différents: prise de conscience, brèves interactions et collaboration (travailler ensemble). L'auteur examine les connaissances actuelles en matière de liens entre l'espace et la dimension sociale et aussi en termes d'aspects individuels du travail en collaboration. L'auteur étudie ensuite le conflit qui est au cœur du travail en collaboration: comment concevoir avec efficacité pour arriver à un équilibre entre le besoin d'interagir et celui de travailler seul efficacement ? La littérature consacrée à ce sujet montre que les caractéristiques et les attributs de l'espace peuvent être manipulés pour augmenter la prise de conscience, l'interaction et la collaboration. Mais des manipulations trop fréquentes ont des incidences négatives sur le travail individuel du fait de l'augmentation du bruit, des distractions et des interruptions du travail en cours. Elles sont surtout préjudiciables aux tâches individuelles complexes qui nécessitent 
une attention soutenue. Les effets négatifs s'ajoutent lorsque le lieu de travail est de plus en plus pénalisé par une surcharge cognitive causée par le stress temporel, une charge de travail accrue et des tâches multiples.

Mots clés: surcharge cognitive, collaboration, conception basée sur l'évidence, efficacité individuelle, interaction, travail de connaissance, prise de conscience du bureau, conception du lieu de travail

\section{Introduction}

Collaboration is perceived as a key to organizational effectiveness in an increasing number of work contexts from service and policy-making organizations to scientific research and development groups (Kraus, 1980; Beyerlein et al., 2003). Responding to this intense interest in collaboration, the design professions, consulting community and furniture industry have developed new workplace concepts, spaces, tools and furnishings intended to support collaborative activities.

Although collaboration is defined as 'working together', effective collaboration entails both individual focused tasks and interactive group work. Accordingly, collaborative work environments require spaces, furnishings and technologies that support both individual focus and group interaction, while also facilitating transitions between these activities. Finding the right balance and types of support for individual and group work requires an understanding of both social and cognitive processes. Unfortunately, the burgeoning body of research on collaboration is highly specialized and not readily available to designers, workplace consultants and manufacturers. As a result, the design of contemporary office environments is often based largely on intuition derived from personal experience or from highly simplified accounts of the academic literature applied without reference to this literature's underlying association of physical design with the nature of work. This often leads to misapplication of research findings from one context to another.

The paper is intended to bridge this knowledge gap. Its objectives are: (1) to identify the key behaviours and activities associated with collaborative knowledge work; and (2) to assess the literature concerning how the physical environment influences these activities and behaviours. It is also important to note what the paper will not do. It will not incorporate the extensive literature on the technology facilitating distributed virtual teams. Although this is an important issue for collaborative organizations, the focus is on the physical workplaces where people spend the majority of their waking hours.

\section{What do knowledge workers do?}

To frame the context for this discussion, consideration needs to be given to what is known about the dayto-day behavioural patterns of knowledge workers.
Peter Drucker coined the term 'knowledge work' in Landmarks of Tomorrow (1959) to describe work that occurs primarily because of mental processes rather than physical labour. Knowledge work tasks include planning, analysing, interpreting, developing, and creating products and services using information, data or ideas as the raw materials. Although knowledge work is perceived as high-level cognitive work, it also includes mundane tasks such as storing and retrieving information, calendaring, returning telephone calls, and composing and responding to e-mail (Suchman, 2000), which can take a considerable time (Reder and Schwab, 1990).

By its very nature, knowledge work is both highly cognitive and highly social. Workers need time alone to think and develop ideas, drawing on their own memory, insight and analytical skills. They also need 'hassle-free' time for non-conscious processing that aids creativity and imagination (Claxton, 2000). Yet, in order for ideas and concepts to become useful to an organization, they must be made available to others for scrutiny and further development. Thus, knowledge work also involves conversation and interaction allowing thoughts embedded in one person's mind to be externalized and accessible to others through writing, speech or graphic visualization. This transfer happens through social networks as people encounter one another throughout the normal working day in both formal and informal settings (Allen, 1977; Backhouse and Drew, 1992; Brown and Duguid, 2000).

Ethnographic research in work settings has begun to identify behavioural patterns that characterize knowledge work. Using behavioural observations, shadowing, in-depth interviews and time utilization records, researchers have identified a number of key work behaviours, including the following:

- Workers have small blocks of uninterrupted time, punctuated by frequent, brief conversations

For instance, Reder and Schwab (1990) found that the average duration of uninterrupted work was less than 10 minutes for professionals in a software development firm. Perlow (1999) found similar results for software engineers, with uninterrupted time lasting less than 30 minutes.

- At any given time, only a portion of tasks are worked on, with multiple tasks being in a state of suspension 
In Reder and Schwab (1990), workers spent about one-third of their time on 'key tasks' (those related to major work group objectives) and frequently switched attention between these and other, less important tasks throughout the day. Other studies show that workers often tend to do what is easy to accomplish in a given time frame or what has attracted their attention, rather than what is important (Backhouse and Drew, 1992; Lahlou, 1999).

- Task switching is common and results, in large part, from interruptions to on-going work

Interruptions result from workers needing to check facts, set up meetings, conduct status checks or get help in order to move their own tasks forward (Perlow, 1999). A unique observational method developed by Lahlou (1999) and colleagues at a research laboratory in Paris uses a small video camera mounted on eyeglasses to observe activity from the worker's perspective. Results from initial studies show that workers switch their focus of attention frequently when distracted by telephone calls or when drawn to something going on outside their workspace.

\section{- People spend most of their interactive time face-to-face}

Ethnographic studies show that face-to-face is the most common form of interaction and communication in a variety of work settings (Reder and Schwab, 1990; Perlow, 1999). For instance, Reder and Schwab found that managers spend about $60 \%$ of their time in face-to-face interactions, and professional workers spend about $25-30 \%$ of their time. Both groups spent about $12 \%$ of their time on the telephone. Similar results were found in a large-scale office study by Brill et al. (2001) using a survey methodology. There is evidence, however, that some types of workers, such as software engineers, are more inclined to use e-mail than either telephone or face-to-face communication (Brager et al., 2000).

- Most face-to-face interactions at work are opportunistic rather than planned

Observational studies show that interactions result largely from movement patterns and spatial visibility that make workers available for recruitment into conversations (Backhouse and Drew, 1992; Penn et al., 1999; Rashid et al., 2004). Interactions often occur in or near personal workstations and on well-trafficked corridors.

- Although workers can store most documents electronically, many still prefer paper

Sellen and Harper (2002) found that many professional workers preferred paper to electronic copy for reading, thinking, planning, editing and reviewing. Workers also like to keep paper documents in piles on their desks and other surfaces in order to keep ideas easily accessible.

- Deliberate movement to engage someone in conversation drops off dramatically after 30 metres Separation by more than 30 metres is equivalent to being in different buildings, if not in different geographical locations (Allen, 1971). Even within this 30-metre range, those nearest to one another communicate more than those at a greater distance. Since Allen's landmark studies on communication patterns in office settings, other researchers have confirmed the importance of propinquity for informal communications (Kraut et al., 1990; Serrato, 2002).

Taken together, these results present a picture of work that is complex, opportunistic, non-linear and improvizational. Research also shows a work context that presents serious cognitive challenges resulting from multitasking, excessive information load and unfinished work (Kirsh, 2000).

The links between (1) physical space, (2) focused individual work and (3) interactive work are reviewed below. Consideration is given to how the features and attributes of space support or inhibit both the ability to concentrate on key tasks as well as the ability to engage with others. The paper is thus divided into three key sections. The first, 'Social dimensions of collaborative knowledge work', focuses on the interactive aspects of collaboration. The second, 'Individual aspects of collaborative knowledge work', focuses on solitary work and behaviours; and the third provides a summary and concluding remarks.

\section{Social dimensions of collaborative knowledge work}

The social dimensions of collaboration include three components: awareness, brief interaction and collaboration (defined as 'working together'). These dimensions differ in purpose and time frame:

- Awareness involves knowing what is happening in the surrounding space as well as the meaning of events and actions. Processing of this information is primarily through peripheral channels and is used to maintain an on-going knowledge of others' locations, activities and intentions (Weiser and Brown, 1996; Gutwin and Greenberg, 2001).

- Brief interaction includes functional communications (e.g. fact checking, passing on information and asking questions) as well as social interactions such as quick personal exchanges, bantering and joking. These types of interactions typically last less than 1 minute (Reder and Schwab, 1990). 
- Collaboration involves two or more people working together over time to produce a joint product or other outcome (Kraut et al., 1990). Collaborations can be long-duration interactions (e.g. problem-solving sessions or demonstrations) that last many hours as well as short-duration interactions that last just a few minutes. Short collaborations often occur spontaneously, for instance, to discuss the importance of new information or to explore preliminary ideas that are later developed (Kraut et al., 1990).

In the following sections, each social dimension (i.e. awareness, informal interaction and group collaboration) is discussed in more detail. The precipitating context (e.g. the organizational and work factors that lead to a need for awareness, interaction and collaboration) and the physical features that influence the collaborative behaviours are considered. In addition, the benefits and costs of awareness, brief interaction, and collaboration are considered, drawing on research from the social and organizational sciences.

\section{Awareness}

\section{Overview}

On-going awareness allows workers to remain in touch with what is going on around them without using focused attention. This 'back channel information' is kept at the periphery until external events capture attention or the user voluntarily switches attention (Weiser and Brown, 1996) in order to focus on the information in the environment, to assess its meaning and to plan future courses of action (Hutchins, 2002).

Although some degree of awareness is likely to be beneficial in all work settings, the appropriate level depends upon the nature of the work and the time in a project or process cycle. Research suggests that high awareness may be beneficial for teams and groups experiencing the following social and cognitive demands:

- dynamic task environment (Hutchins, 2002)

- sense of urgency or intense time pressures (Teasley et al., 2000; Cachere et al., 2003)
- need to share information and obtain rapid feedback to questions (Marks, 2002; Cachere et al., 2003)

- high need for transparency of tasks and operations to support coordination (Horgen et al., 1999)

Examples of high-awareness workplaces include trading floors, emergency control rooms and air traffic control towers.

Interestingly, we are learning a great deal about workspace awareness from computer scientists. As they develop groupware tools and other technologies for distributed teams, they need to identify features in the real work setting that could usefully be emulated in the computer workspace to enhance the sense of presence when people cannot be face-to-face (Gutwin and Greenberg, 2001; Rognin and Bannon, 2001).

The Workspace Awareness Research group, University of Calgary, Alberta, Canada, identifies several key elements in workspace awareness. Although the group uses this framework for the development of groupware for distributed teams, it is highly relevant to the design of real workspaces. Table 1 is derived from the group's framework.

\section{Links between awareness and physical space}

Visual and aural accessibility are key environmental contributors to workplace awareness (Gutwin and Greenberg, 2001). According to Gutwin and Greenberg, overhearing conversations and people doing 'self-talk' as they work allows assessment of when someone needs help. The tone, loudness, specific words and context in which words are spoken also contribute to a broad understanding of what is going on and its potential significance. Because conversations can also be distracting, overhearing may be most valuable when work is highly interdependent and when the collocated people are working on the same or similar projects. In such cases, conversations are more likely to be relevant to others in the group (Teasley et al., 2000).

Table 1 Elements of awareness

\begin{tabular}{ll}
\hline Element & Relevant questions addressed \\
\hline Identity & Who is here? \\
Location & Where are they? \\
Activity & What are they doing? \\
Interactants & With whom are they interacting? Are they interacting in person? \\
Content & Are they interacting on the telephone? \\
Time & What are they talking about? \\
Relevance & How long are they likely to be interacting? \\
Expectations & What relevance does the conversation have for me? \\
Objects/technologies & What might they do next? What might they need me to do? \\
\hline
\end{tabular}


The extent of access into and within a space is influenced by the presence or absence of doors, walls, windows, workstation panels, mirrors, light, the size of the space and physical proximity of workers (Archea, 1977). The scale of space and proximity of co-workers primarily affect the sensory modes used to track information. For instance, at close distances, all sensory modes are relevant. At further distances, vision becomes most important. Furthermore, behavioural factors, such as orientation with respect to lines of sight, affect the extent to which visibility is taken advantage of (Archea, 1977).

The visibility of information and artefacts used in work also contributes to overall awareness. Because knowledge work activity is largely cognitive and does not leave physical traces, it may be increasingly important to have artefacts and visual displays of information to aid coordination, memory and understanding the work as a whole (Lahlou, 1999; McGee, 2002). McGee argues that information displays are important to reconstructing a plan or reasoning behind a particular piece of work. Often these elements are a more effective learning tool than the final, highly edited and revised version of knowledge work products that are constructed electronically.

Other research on situation awareness focuses on how the arrangement of equipment and physical layout of the task environment influence access to information and coordination of activities among group members (Artman, 2000). Displays and artefacts that can be readily seen and evaluated by group members create a greater degree of shared awareness.

\section{Potential benefits and constraints}

High levels of workplace awareness have both benefits and potential problems for work. On the positive side, research studies show benefits for work process and learning. For instance, research on software development teams housed in project rooms found that the open environment aided the team members' ability to answer questions, coordinate actions, share information rapidly and plan future responses (Teasley et al., 2000). High awareness space also aids tasks that require close monitoring to assess problems and control the quality of work (Horgen et al., 1999).

Integrating newcomers into an organization may also benefit from high awareness, regardless of the specific nature of work. Fried et al. (2001) found that new employees in an organization were much more satisfied with an open-plan workspace than those who had been with the organization for many years, regardless of job complexity. The researchers suggested that new employees might be learning about the organization and how to carry out their work by watching and overhearing others. Although this is a potential expla- nation, the researchers did not test this hypothesis. Further research is clearly needed to clarify the links between organizational learning and workspace features and attributes.

Key problems of high-awareness environments have been documented in the research going back to the landscaped office design (McCarrey et al., 1974). Problems include loss of privacy, loss of confidentiality, distractions and interruptions (Sundstrom et al., 1982; Brill et al., 2001).

However, there is some indication that a highly open environment might lead to reduced interruptions and distractions due to the greater availability of nonverbal and behavioural cues that modulate interaction (Allen and Gerstberger, 1973; Backhouse and Drew, 1992; Becker and Sims, 2001). When people are focused on an individual task, their posture, eye gaze and demeanour indicate they are not available for conversation. However, if they look up, make eye contact or walk around, others are more likely to perceive them as available for interaction.

\section{Summary}

Table 2 summarizes the conditions that warrant high awareness, the physical features and attributes that aid awareness, the potential benefits and problems of high workplace awareness.

\section{Brief interaction Overview}

Numerous studies show that workers spend between 20 and $35 \%$ of their time in interactions with colleagues (Reder and Schwab, 1990; Perlow, 1999; Brill et al., 2001). These interactions tend to be unscheduled and occur in many locations, including individual workstations, hallways, doorways and near central resources. Brief interactions can be both intentional (looking for a specific person with whom to talk) or unintentional (running into someone in the hallway). They are largely information exchanges, but also include interactions that support the development and maintenance of collaborative relationships.

The research on communication and interaction has occurred in a limited range of work settings, such as scientific research and development (Allen, 1977; Serrato, 2002), software engineering (Reder and Schwab, 1990; Perlow, 1999), and creative professions such as design or advertising (Backhouse and Drew, 1992; Penn et al., 1999). There is less research on interactive behaviours in traditional office settings or in other professional contexts, such as law or policy development. 
Table 2 Workplace awareness

\begin{tabular}{|c|c|c|c|}
\hline Precipitating conditions & $\begin{array}{l}\text { Features and attributes } \\
\text { of space that influence } \\
\text { awareness }\end{array}$ & Key benefits & $\begin{array}{l}\text { Potential constraints and } \\
\text { problems }\end{array}$ \\
\hline $\begin{array}{l}\text { Dynamic task environment } \\
\text { Sense of urgency } \\
\text { Need to share information } \\
\text { and get feedback rapidly } \\
\text { High need for transparency of } \\
\text { tasks and operations to } \\
\text { support coordination }\end{array}$ & $\begin{array}{l}\text { High visual access into } \\
\text { surrounding spaces } \\
\text { High aural access to } \\
\text { surrounding spaces } \\
\text { Proximity to others Shared } \\
\text { information displays }\end{array}$ & $\begin{array}{l}\text { Improved coordination } \\
\text { Rapid information sharing } \\
\text { Potential for increased } \\
\text { learning by observing and } \\
\text { overhearing } \\
\text { Ability to answer questions } \\
\text { rapidly } \\
\text { Ability to perceive problems } \\
\text { and to go someone's aid }\end{array}$ & $\begin{array}{l}\text { Loss of privacy } \\
\text { Loss of confidentiality } \\
\text { Increased distractions from } \\
\text { people talking nearby } \\
\text { Increased interruptions }\end{array}$ \\
\hline
\end{tabular}

The available research suggests that high levels of brief, informal interaction are valuable under the following circumstances:

- when the task has a high level of uncertainty (Katz and Tushman, 1979)

- when groups are faced with high time pressure to produce or upgrade a product or service (Teasley et al., 2000)

- for multidisciplinary groups that must gain rapid understanding of one another (Allen and Gerstberger, 1973; Cachere et al., 2003)

- when information from external sources needs to be shared rapidly and assimilated in the organization (Katz and Tushman, 1979)

- when innovation is a high priority and when performance is related to generating, sharing and assessing new ideas, and developing new solutions (Allen, 1977; Katz and Tushman, 1979)

There is also evidence that intergroup interaction related to knowledge sharing is most beneficial when knowledge is not codified, i.e. when 'know how' is experiential and tacit rather than attained by following manuals and procedures (Hansen, 2002). Hansen argues that maintaining relationships and networks reduces the time needed for task accomplishment and should be encouraged only when the value of information gained from the relationships is high. This is most likely for tasks with a high experiential and tacit component or in a dynamic, uncertain context. High levels of communication and informal interaction are less essential for tasks with known and regularized procedures.

Even in these circumstances, however, interaction with colleagues is important for coordination as well as for the development of trust and social relationships at work (Gabarro, 1987; Tsai and Ghoshal, 1998). At a personal level, friendships and a sense of belonging at work fulfil a basic human need for continuing and sup- portive relationships (Baumeister and Leary, 1995; Lawrence and Nohria, 2002). Evolutionary psychologists argue that on-going social exchange and gossip are deeply ingrained in human behaviour and may have evolved to aid understanding of other individual's mental states (Dunbar, 1997) as well as to solidify group ties (Wilson et al., 2000). At the organizational level, friendships at work have been shown to increase overall satisfaction and commitment (Buckingham and Coffman, 1999) and to promote positive citizenship, such as helping others and being involved in organizational activities (Organ and Ryan, 1995).

\section{Links between brief interactions and physical space}

Ethnographic and space syntax analysis research has begun to identify both spatial features and worker behaviours that distinguish high and low interaction spaces.

For instance, an ethnographic study by Backhouse and Drew (1992) provides insight into how behavioural patterns and the environment jointly precipitate interaction. Using video cameras and onsite observations, Backhouse and Drew found that $80 \%$ of interactions in a design office were unplanned and occurred as a result of movement patterns and the perceived 'availability' of workers for recruitment into a conversation. Availability was determined largely by whether or not the person appeared to be involved in focused work. A person standing or looking around in a workspace as well as those walking were considered more 'available' and were therefore more likely to be recruited into a conversation than a person working head down or talking on the telephone. Given the importance of recruitment to interaction, Backhouse and Drew suggest that space should be designed around 'strategic positions' and their actual and potential lines of sight. They argue that an individual's line of sight and visibility will influence his/her ability to recruit or be recruited and this in turn influences the extent to which they engage in unplanned interactions. 
Rashid et al. (2004), in a study of four office buildings, also found that interactions were highly correlated with what they called 'co-presence', the number of individuals who can be seen from any point along a given circulation path. Using space syntax analysis combined with behavioural observations, they found that co-presence was a more important predictor of face-to-face interactions than movement patterns. They also found that people in all four office buildings interacted primarily in individual workstations rather than in spaces intentionally designed for collaboration.

Layout and circulation were also important predictors of interaction in a study of research scientists by Serrato (2002). Using a behavioural sampling methodology, Serrato found differences in communications patterns related to differences in interior layouts. Each scientist in the study responded to ten random pages per day and recorded their location and activity on a hand-held computer. If they were interacting faceto-face, they also recorded whether the person with which they were talking was a group member, administrative personnel or outsider. Scientists in the study worked for the same organization, but were housed in two different buildings with different layouts. Scientists in the building with a maze-like layout, dispersed work groups and low visibility had fewer spontaneous interactions with other scientists than their colleagues doing similar work in the building with clustered workstations, higher levels of interior visibility, a high degree of proximity among team members and a circulation system with a strong central path.

Similar results were found by Penn et al. (1999) using space syntax methodology coupled with survey techniques. They found that variation in the spatial patterns of different parts of the building was associated with differences in the perceived 'usefulness' of workers by those in other research groups. Layouts with the most connections to other spaces had more interaction between workers, and workers were perceived as more useful to one another.

Proximity is another key determinant of the level of informal interaction in an organization. The original work on this topic, conducted by Thomas Allen and colleagues in the 1960s and 1970s, found that communication between workers decreased rapidly with distance (Allen, 1971, 1977). Beyond 30 metres, there was very little spontaneous interaction. Allen also found that interactions decreased with the complexity of the movement path. As pathways become more complex, with more corners and more connecting pathways, interactions decrease rapidly. Allen referred to this as the 'nuisance factor'. Penn et al. (1999) also found that communication behaviours dropped off rapidly when people were at a greater distance from an entry way or on a more indirect pathway.
A pre- and post-study of professional workers in an office setting found that proximity was important to friendship opportunities and information exchange (Szilagyi and Holland, 1980). Workers were studied in both old and new offices that varied in the degree of social density. Those who experienced an increase in social density (measured as the number of employees within a 50-foot walking distance) had higher ratings of friendship opportunities and information exchange than workers who experienced a decrease in social density from the old to the new space. There were no changes in these outcomes for a group of workers who experienced the same social density pre- and post-study.

Kraut et al. (1990) also found that proximity was a critical factor in determining who published reports together in a research and development (R\&D) organization. They studied 93 researchers in a large organization with two research laboratories 40 miles apart. They found that $36 \%$ of collaborations were between researchers on the same floor, and that $46 \%$ of collaborations were between researchers on the same corridor. Thus, $82 \%$ of the collaborations took place between those on the same floor or same corridor, even though they made up only $12 \%$ of pairs in the sample. Being on a different floor had the same effect as being in the building 40 miles away. Interestingly, the scientists studied by Kraut et al. (1990) did not believe the collaborations had a positive impact on their work. They rated their solo academic papers as better and more important than their collaborative papers. According to survey results, the researchers sought out collaborative partners for social, not intellectual, reasons. The topic of the paper also mattered. Researchers were more likely to work with a colleague on an empirically based paper than on a theoretical paper due to an easier division of labour.

Although the evidence cited above shows good links between interaction and physical space, this relationship can be modified by organizational structure. For instance, in hierarchical organizations and in organizations with high levels of internal competition between work groups, information sharing may be constrained despite design intentions (Tsai, 2002).

Surprisingly, there is little evidence from the studies cited above that presumed 'natural' meeting areas (such as coffee nooks, copy rooms, etc.) promote interaction unless these are on well-trafficked pathways. That is, the pathway seems more important than the destination.

\section{Potential benefits and constraints}

Research on the benefits of interaction has focused on mutual understanding, learning, decision-making and relationship maintenance. It is important to realize, however, that research on the benefits of interaction has been conducted by social and organizational sciences that have largely ignored the relationship to 
physical space. Thus, many of the papers cited herein deal with benefits or constraints from a strictly behavioural and work process perspective and do not take physical space into account. Nonetheless, if space can be shown to influence interaction (as done above), then it is likely that outcomes discussed in the present section can be achieved, in part, through spatial design.

From a functional perspective, informal face-to-face interactions aid understanding and problem-solving due to the enriched context, including facial expressions, gestures, posture, appearance and reactions of other people (Kendon, 1990). Face-to-face interaction is also more flexible and can respond better to ambiguity and uncertainty (Allen, 1971).

Brief, informal interaction may also aid organizational and individual learning by spreading knowledge broadly in the overall social system (Gabarro, 1987; Rizzo et al., 1999; Bagnara and Marti, 2001). Informal interactions may be a valuable mode of learning because a large amount of any organization's knowledge resides in people's heads rather than in written form and it is easier to access by asking questions than by searching for paper documents or electronic information (Bagnara and Marti, 2001). This makes it more likely that people wanting information rapidly will seek out a colleague rather than use a formal knowledgemanagement system. Furthermore, by consulting with a colleague, one also has the ability to follow up with additional questions as well as to explore the meaning and relevance of the information.

Research on work groups also shows that high levels of information flow and information sharing is valuable for group decision-making, especially when information is shared before the need to make a decision (Kerr and Tindale, 2004). New information is less valuable when it is introduced at a decision point because group members have less time to think about it and integrate it into their individual problem perspective. High information sharing also contributes to mutual awareness of 'who knows what' (Moreland and Argote, 2003).

Building and maintaining relationships and camaraderie among workers also benefit from frequent interaction. For instance, Carletta et al. (2000) found that teasing, joking and work banter increased positive affect at work and created a sense of solidarity among group members. There is also evidence that informal social relationships foster integration of work processes between groups (Gutpa et al., 1999).

Although there are numerous benefits of interaction, problems also exist largely because of distractions and interruptions. Overheard conversations have a high potential to be experienced as 'irrelevant speech', defined as speech not related to the individual's task (Jones and Morris, 1992). Irrelevant speech is detrimental to reading comprehension, short-term memory, proofreading and mathematical computations (Jones and Morris, 1992; Banbury et al., 2001). Distractions may also interfere with the cognitive flow state that characterizes intense engagement with work tasks (Csikszentmihalyi, 1990). Distractions from people talking are particularly difficult to ignore due to potential for salient information. Overhearing people talk, especially in a shared context, triggers an involuntary, reflexive response that switches attention from the task to the talking individuals (Pashler et al., 2001). In contrast, working in a café or other public place is less distracting because the surrounding conversations are not likely to be meaningful or informative to the listener.

Although work can continue with distractions, albeit with increased mental effort, interruptions are detrimental because they cause work to come to a halt. Most interruptions are due to people stopping by one's workspace or from telephone calls (Reder and Schwab, 1990). Interruptions influence work process in several ways. An interruption may require a change in one's action plan or strategy for achieving the original goal, it may increase memory load or it may increase effort to speed up performance (Zijlstra et al., 1999). Interruption of complex work requires a longer time to reorient (Pashler et al., 2001), and continued interruptions are likely to have negative effects on mood that reduce the motivation to resume work (Zijlstra et al., 1999).

For simple tasks, interruptions appear to have much less impact and may possibly be stimulating if the work being performed is routine and judged as boring by the worker (Zijlstra et al., 1999). Research also suggests strong individual differences in response to distractions, with introverts more likely to be bothered than extroverts (Belojevic et al., 2001), as are those who score high on noise sensitivity and annoyance measures (Kjellberg et al., 1996).

Interruptions may also make it difficult for workers to get tasks completed on time. Ethnographic research in a software development company found that people frequently interrupted by others complained about the inability to get work done (Perlow, 1999). In an analysis of the firm, Perlow distinguished between 'lost collective time' and 'lost individual productivity'. Perlow (1999, p. 75) speculated that both can lead to decreased overall work effectiveness:

Effective time use for a group requires a sufficient number of interactive activities to achieve the group's goals, but it also requires the synchronization of these interactive activities to best insure that they occur at times that do not continuously interrupt group members' individual activities.

Perlow's research tested the impact of an organizational intervention designed to provide several hours 
each day of uninterrupted time. Although the quiet time worked for a while, people gradually began to ignore it when they needed to talk to someone, with the result that quiet time reverted to the pre-existing behavioural pattern.

In addition to the functional difficulties associated with interruptions and distractions, there is growing evidence for health and quality of life problems. Workers often increase effort in the face of challenges to their work and this can lead to psychophysiological stress (Tafalla and Evans, 1992; Evans and Johnson, 2000). In addition, people often work extra hours to compensate for lost efficiency associated with distractions, interruptions and time spent communicating with others (Teasley et al., 2000). This contributes to work-life imbalance that is a growing concern in many organizations.

\section{Summary}

Table 3 summarizes the precipitating conditions, links to physical space and benefits of and constraints associated with informal interactions.

\section{Collaboration}

\section{Overview}

Collaboration involves at least two people interacting over time to produce a joint product or other outcome (McGrath, 1984; Kraut et al., 1990). Collaboration includes both long-duration interactions (e.g. problem-solving sessions and demonstrations) and short-duration interactions that might last just a few minutes rather than hours or days (e.g. quickly reviewing documents or discussing a new idea).
Social science researchers differentiate between 'team' and 'group' work. In general, teams have a high degree of interdependence between members, a specific goal that all are working toward and the need for frequent coordination among actions, responses, activities and tasks (Zalesny et al., 1995). Teams work jointly to solve problems, develop plans, discuss new ideas, coordinate efforts and deal with emerging crises (Katzenbach and Smith, 1999). Teams benefit from collocation, which aids on-going interaction, information sharing, crisis management and spontaneous meetings.

In contrast, work groups tend to rely more on individual tasks that are integrated at specific points. Groups, such as committees or task forces, include members from different parts of the organization and are not likely to be collocated. Thus, their interactions are largely electronic or take place in scheduled meetings. Group work may have bouts of high face-to-face interactivity when there is a need to merge ideas and tasks, but even these meetings are likely to be scheduled in advance.

Given the differences between teams and groups, a key to developing effective collaboration spaces is to understand the nature of the work, typical group processes and other conditions that would lead to differential workplace designs. Physical features that are appropriate for the collaborative activities of traditional work groups are likely to be different than conditions for project teams, product breakthrough teams or multidisciplinary scientific R\&D teams.

The specific features of collaborative spaces and their successful implementation vary according to the

Table 3 Brief interaction

\begin{tabular}{|c|c|c|c|}
\hline Precipitating conditions & $\begin{array}{l}\text { Features and attributes of } \\
\text { space that influence brief } \\
\text { interactions }\end{array}$ & Key benefits & $\begin{array}{l}\text { Potential constraints and } \\
\text { problems }\end{array}$ \\
\hline $\begin{array}{l}\text { High need for coordination } \\
\text { Dynamic task environment } \\
\text { Time pressure } \\
\text { High task uncertainty } \\
\text { Multidisciplinary work } \\
\text { groups } \\
\text { Need for rapid assimilation } \\
\text { of new information } \\
\text { High demand for innovation }\end{array}$ & $\begin{array}{l}\text { High visibility into work } \\
\text { areas } \\
\text { High visibility into and from } \\
\text { individual workstations } \\
\text { Location of workstation on } \\
\text { primary circulation path } \\
\text { Physical access from } \\
\text { multiple areas } \\
\text { Circulation systems that } \\
\text { funnel movement rather } \\
\text { than disperse it } \\
\text { Proximity of workers to one } \\
\text { another } \\
\text { Location of natural meeting } \\
\text { places on key corridors }\end{array}$ & $\begin{array}{l}\text { Increased learning } \\
\text { Improved communication } \\
\text { effectiveness } \\
\text { Increased process } \\
\text { integration across } \\
\text { work units } \\
\text { Improved group } \\
\text { decision-making } \\
\text { Increased ability to get/give } \\
\text { help when needed } \\
\text { Increased awareness of } \\
\text { 'who knows what' } \\
\text { Increased camaraderie } \\
\text { Increased ability to develop } \\
\text { friendships and close } \\
\text { work relationships }\end{array}$ & $\begin{array}{l}\text { Increased distractions due } \\
\text { to people talking nearby } \\
\text { Increased interruptions } \\
\text { from people needing } \\
\text { information or assistance } \\
\text { Reduced time for individual } \\
\text { task accomplishment } \\
\text { due to distractions and } \\
\text { need to maintain bonds } \\
\text { Increased need to work } \\
\text { extra hours to } \\
\text { compensate for reduced } \\
\text { individual task time } \\
\text { Potential for increased } \\
\text { stress }\end{array}$ \\
\hline
\end{tabular}


nature of the work. Key considerations include the following:

\section{- On-going communication needs}

The need for rapid, continuous information sharing, group problem-solving, monitoring progress and pressures for reduced product/project time are factors favouring easily accessed group workspaces, shared information displays and dedicated project rooms (Allen, 1977; Katzenbach and Smith, 1999). Creative problem solving by the group may also benefit from group tools and artefacts (Sutton and Hargadon, 1966; Hargadon, 1999). In contrast, work groups with an intermittent need for interaction (such as committees) may function effectively with scheduled meetings in traditional conference rooms.

\section{- Cognitive complexity of the group task} Multidisciplinary understanding and complex problem-solving are likely to require group technologies and tools, including information displays, surfaces for tracking progress, shared databases and visualization technologies (Teasley et al., 2000; Chachere et al., 2003). Under these circumstances, enclosed project rooms may be desirable.

\section{- Task structure}

Groups with highly interdependent and parallel tasks are likely to benefit from spaces that support on-going coordination, rapid problemsolving and prompt feedback on information requests (Chachere et al., 2003).

However, the nature of work alone is not sufficient to guarantee that spaces designed for collaboration are effective. It is increasingly evident that organizational factors, such as decision-making structure, behavioural norms and reward structure can inhibit space use.

A reward structure based on individual achievement may reduce motivation to share valuable information and raise concerns about how individual effort can be evaluated relative to group performance (Teasley et al., 2000). Also, behavioural norms based on individual effort and working alone may make it difficult for workers to shift to a more collaborative work pattern without organizational supports in place.

Collaborative group work, especially cross-unit work, is more likely to succeed when there are few structural barriers between groups and when information flows and decision-making are dispersed rather than being centralized and hierarchical (Beyerlein et al., 2003). Beyerlein et al. argue that effective collaboration is possible only when organizational culture places high value on shared power, egalitarianism, active information sharing and commitment to the success of all workers.

\section{Links between collaborative behaviours and physical space}

Research on the links between collaborative behaviours and physical space has focused on group workspaces and supporting artefacts and technologies. Specific space solutions discussed below include bullpens, informal team spaces, the 'non-territorial' office and project rooms.

\section{Bullpens}

Open bullpens are also commonly used to encourage interaction and communication among group members. As defined by Becker and Sims (2001), a bullpen is a group of four to 12 desks in an open space, without partitions or dividers. A similar concept is the 'pod' - a group of four to six workstations surrounded by high panels around the perimeter of the group. The key feature of either space is high visual and aural access to group members.

\section{Informal group spaces}

A common workplace solution to enhance collaboration is the provision of informal group spaces adjacent to or interspersed among personal workstations. The spaces have moveable furnishings, are located in the open and are often shared by different work groups. The intent of the space is to support spontaneous meetings and informal work.

\section{Non-territorial, high-mobility offices}

Non-territorial, high-mobility offices eliminate assigned workstations, providing in their place a variety of spaces that can be used by individuals or groups. Many such spaces also eliminate walls and barriers to encourage visual and aural access among workers. Current applications use mobile technologies (laptops, wireless connections, Internet telephones) that make it easier to keep in touch with colleagues and to move work from space to space.

\section{Project rooms}

A fourth approach to collaboration involves housing a team in a dedicated project room for specific periods, ranging from project duration to shorter, intense interaction periods. Project rooms normally have shared information displays for tracking project assignments and progress, project files, access to organizational databases, and space for individual work.

Although the spaces designed for collaboration vary, they share several key features: aural and visual openness, shared information displays, mobility within the space, and easy movement between the individual and group work. They differ primarily in the provision of supporting tools and technologies, and the ability to have multiple sized groups working simultaneously. 
For instance, project rooms place a greater emphasis on shared information displays and data access, and they also enable full and small group meetings as well as individual work within the same space.

\section{Potential benefits and constraints}

This section reviews research on the effectiveness of the various types of collaborative spaces. Given the high interest in the topic of collaboration, there is a surprising dearth of research on the link between collaborative work processes and space. The vast majority of spatial research has focused on brief interaction and communication patterns. Nonetheless, the available studies offer insights about spaces specifically designed to encourage group work processes.

\section{Bullpens}

Research on interaction patterns among workers in pods and bullpens as compared with closed offices or workstations with high panels shows that the frequency, duration and nature of interactions vary across the settings (Becker and Sims, 2001). Workers in the bullpen and pod workspaces had the highest frequency of interaction at 1.75 to 2.00 interactions per person/hour in the bullpen and pod, compared with less than 0.25 interactions per person/hour in either the closed offices or the high panelled workstation. The duration of interactions also varied, with less than 1 minute per interaction, on average, in the pod and bullpen, and 6 minutes per interaction, on average, in the closed office.

The topic of conversation also varied. In the bullpen space, $62 \%$ of the interactions were about work and $23 \%$ were non-work related. In contrast, $80 \%$ of the conversations in high panelled workstations were work related and only $6 \%$ were about non-work topics. Becker and Sims (2001) do not provide an explanation for these differences. (There were no comparable data on enclosed offices because conversations are more difficult to overhear.) The authors suggest that non-work-related talk helps to build social relationships and a sense of camaraderie, but they provide no specific evidence regarding relationship development in different spaces.

Becker and Sims (2001) argue that the open bullpen and pod environments are appropriate for most work settings due to the high value of communication. They further argue that few jobs require long periods of focused attention. When concentration is needed, workers can easily move to quiet spaces provided elsewhere in the office.

Although the frequent, non-work interactions are important for getting to know people and to build a sense of team spirit, this does not necessarily build deep trust that comes from feeling secure enough in a relationship to disclose personal feelings and problems as well as sensitive business issues (Gabarro, 1987). This requires privacy rather than openness.

\section{Informal group spaces}

An evaluation of informal spaces in a large Silicon Valley, California, US, high-technology company shows mixed results on collaborative behaviours (Brager et al., 2000). The group spaces were located in hallways or nooks adjacent to private offices in several buildings. The locations were deliberately chosen to make it easy for people to access the spaces and also to provide visibility so that others could join in as desired. Although the specific designs varied, each was intended to look more like a den than a conference room, with comfortable, movable chairs and small tables. Most also had white boards. The rationale behind the space was simple: because collaboration was of strategic value to the company, spaces that made it easy to have spontaneous and informal interactions would be beneficial. A total of 238 workers completed a web-based survey that investigated work patterns and satisfaction with the team spaces.

Results show that the informal spaces were seldom used. In large part, this was due to a mismatch between the design and the nature of work at the firm. The survey respondents (who were computer programmers) spent the vast majority of their time working alone rather than interactively. Furthermore, their interactions with others occurred primarily by e-mail and telephone rather than face-to-face. Another problem was that many of the workers located near the informal meeting spaces did not work together they often belonged to several teams and worked with people in many locations. When they wanted a meeting, they arranged for a conference room.

Other problems with the spaces also surfaced, including acoustical distractions, a lack of appropriate functionality and a concern that use of informal spaces would be perceived as 'not working'. From a functional perspective, when workers convened as a group, they often used computer workstations and conference telephones to connect in geographically dispersed team members. Neither of these technologies was available in the informal group spaces. Not surprisingly, given these issues, the informal group spaces were seldom used. Interestingly, the one space that did get used regularly was at the end of a hallway and was surrounded by people who worked together on the same project. Because the team was collocated and separated from other groups, it was possible for its members to use the informal space much more like a project room where they could display information and keep project materials posted for others to see. 
Rashid et al. (2004) also found that spaces deliberately designed for informal interaction were seldom used. In a behavioural analysis of workers in four offices, they found that most interactions occurred in individual workstations, even though spaces were provided for informal and spontaneous group work.

\section{Non-territorial, high-mobility offices}

Allen and Gerstberger (1973) used daily communication logs to assess interaction among a small group of R\&D scientists before and after a move from conventional office space to a 'non-territorial space'. The office eliminated individual workstations, replacing them with scattered tables and workbenches. Walls in the office were removed to provide visual openness within the office setting and to give easy access to colleagues in an adjacent laboratory. Semi-enclosed quiet rooms were also provided for quiet work. The results showed an increase in the number of interactions per person and in the number of individuals with whom they interacted in the non-territorial office as compared with the traditional setting previously occupied. In contrast to their expectations, the workers were significantly more satisfied with the non-territorial space than with the previous office. They felt that the space supported privacy and concentration more effectively than was expected. The researchers suggest that the positive findings may be due to the scientists being previously housed in shared offices. In the non-territorial, they were better able to control distances to co-workers, and thus be able to interact or work alone as desired. The researchers suggest that workers in the non-territorial space were better able to use behavioural signals indicating when a person wanted to work alone. Allen and Gerstberger also found that the scientists used different spaces for different activities. No one spent more than $50 \%$ of the time at a single table, but instead had two or three preferred places.

The positive results reported by Allen and Gerstberger inspired replications of the non-territorial office concept. In one of the best-known examples, the advertising firm Chiat-Day adopted a non-territorial application for both its Los Angeles and New York offices. Key goals of the design were to improve collaboration, to build a 'collective intelligence', to encourage creativity, to improve quality of work and to retain high-quality workers (Sims et al., 1998). The staff did not have permanent workspaces, but instead were encouraged to move around during the day and to work in different spaces as their tasks and needs changed. In addition, they could work at home or at a client's office. The workspaces in the two buildings included project rooms, a 'club house' with comfortable furnishings, cafés and ad-hoc individual workstations (carrels and cubicles). Workers had portable files and laptop computers that were checked out when they came to work and carried with them during the day.

A case study by Sims et al. (1998) found mixed results for the Chiat-Day workplace. On the positive side, workers reported increased access to one another and increased communication. On the negative side, workers complained about a lack of spaces to get away and think, inconveniences associated with storing their work every night, difficulties concentrating due to noise and interruptions, and the need to search frequently for people because everyone was encouraged to move around. In fact, the New York City office implemented 'peer policing' to stop individuals and groups from occupying specific spaces. Due to growing employee dissatisfaction, the non-territorial workplace was abandoned and gave way to a more traditional office setting in both New York and Los Angeles. In addition to the problems noted above, Brown and Duguid (2000) also suggest that high mobility may reduce the benefits that accrue from the 'predictable presence' of colleagues who are regularly available for interaction and relationship development.

\section{Project rooms}

Research on project rooms has focused on software engineers and scientific teams. Little information is available on other types of work groups.

A 'radical collocation' experiment by Teasley et al. (2000) studied software development teams housed in large rooms rather than in traditional individual workstations with conference rooms for meeting. The experimental teams were working on short-duration projects (four months) and were based in the team room for the entire project. Each team room included a large central table, white boards, flip charts and individual workstations with computers arrayed along the walls. Additional conference rooms were available close by for each team.

The experiment was designed to find out whether high visibility and group work tools could improve communications and reduce time to market without negatively effecting concentrative work. Measures included programming productivity, satisfaction, experience and use of time. The researchers found that compared with company baseline data, the collocated teams had significantly reduced product cycle time.

Behavioural observations showed that being in the same room facilitated discussions, problem-solving at the white board, simultaneous small group meetings and status updates. The key problems with the space, as identified through a survey, were a loss of privacy and distractions from nearby conversations. Team 
members needing to work alone used ad hoc spaces or adjusted their work hours to come in early or stay late. When privacy was desired, team members left the room for other spaces. The biggest concern of the workers, however, was not the workspace but rather a fear that individual contributions to the project would not be recognized by managers.

Another approach to project rooms is the 'extreme collaboration' space at NASA's Jet Propulsion Laboratory (JPL) in Pasadena, California. The space at JPL incorporated a variety of computer technologies to aid collaboration, including data visualization, shared spreadsheets, large interactive graphic displays for modelling and simulation tools. Each person on the team also had an individual workstation in the room, thus enabling individual work to proceed in concert with the group work.

The collaborative workspace was designed to aid mission planning and proposal development at NASA. The room was not continuously occupied, but rather was used for design sessions lasting several hours at a time. Each design session had a designated facilitator who developed an agenda and monitored the session's progress. The facilitator called whole group meetings as warranted, and also helped to form small groups to deal with specific emerging issues.

The XC space has captured attention because of its impact on task duration - the JPL team has consistently reduced the time for design proposals from a typical three to nine months to several days (Marks, 2002; Chachere et al., 2003).

Behavioural analysis of the team using interviews, observations and surveys showed that the key factor in the success of the space was the greatly reduced time between an information request and a response. Chachere et al. (2003) found that the average time taken to answer a question was less than 1 minute versus several days for traditional teams. In addition to the reduced latency between question and response, the room also enabled simultaneous 'sidebar' conversations between small groups to share information or solve emergent problems in real time. Given the intensity of the interaction and cognitive demands of 'extreme collaboration', mental fatigue was commonly experienced.

Unfortunately, JPL research did not address the question of whether the improvements in timeliness had any effect on the quality of the work product.

Although extreme collaboration spaces are limited at present to scientific and engineering groups, Chachere et al. suggest that similar spaces might be more widely applicable, especially for design and project work, as a means to tighten collaboration and make it more focused and effective.
Noting that many organizations might be tempted to employ extreme collaboration practices to reduce project time, Chachere et al. argue that adoption is neither simple nor applicable to all teams or organizations. They identify several organizational, process and cultural factors necessary to employ effectively extreme collaboration:

- highly interdependent and parallel tasks

- availability of shared databases and electronic displays

- effective knowledge network that enables the required information to be immediately available when needed

- flat organizational hierarchy that reduces organizational barriers and management intervention

- ability of participants to command the respect of others in the group

- high valuation of collective achievement rather than individual achievement

- well understood procedures and goals

- ability to communicate in small groups as well as a whole team

\section{Summary}

Table 4 provides a summary of the different types of collaboration spaces as well as the key environmental features, benefits and constraints associated with each type of space. The research summarized in this section and in Table 4 suggests that the design of collaborative space should derive from a careful consideration of the context and the nature of the work, especially the on-going communication needs, the cognitive complexity of the group work and the extent to which the work is truly mobile.

\section{Individual aspects of collaborative knowledge work}

As noted above, collaboration is defined as a system of behaviours that includes individual, focused work as well as interaction. To be effective team members, individuals must have the time, space and tools to do work that can only be done alone, such as reading, writing, thinking, searching for information and synthesizing information into internal knowledge structures. While many individual knowledge work tasks can be carried out effectively in the presence of on-going activity and noise, other tasks cannot. Work that requires focused attention, comprehension, 


\begin{tabular}{|c|c|c|c|}
\hline $\begin{array}{l}\text { Workspace type and } \\
\text { precipitating conditions }\end{array}$ & $\begin{array}{l}\text { Features and attributes of } \\
\text { space that influence } \\
\text { collaboration }\end{array}$ & Key benefits & Problems and constraints \\
\hline $\begin{array}{l}\text { Bullpen or pod } \\
\text { Group members need to } \\
\text { share information } \\
\text { continually rather than } \\
\text { through group meetings; } \\
\text { frequent interaction } \\
\text { between neighbours is } \\
\text { desirable. }\end{array}$ & $\begin{array}{l}\text { Workstations clustered } \\
\text { together } \\
\text { No partitions or barriers } \\
\text { within the group } \\
\text { May have partitions } \\
\text { surrounding the group }\end{array}$ & $\begin{array}{l}\text { Easy communication among } \\
\text { group members } \\
\text { Increased ability to read } \\
\text { signals of others' } \\
\text { availability Increased } \\
\text { coordination ability }\end{array}$ & $\begin{array}{l}\text { Distracting to work that } \\
\text { requires thoughtfulness } \\
\text { and focused attention } \\
\text { Reduced privacy }\end{array}$ \\
\hline $\begin{array}{l}\text { Informal teaming spaces } \\
\text { Group members often } \\
\text { need to meet } \\
\text { spontaneously for } \\
\text { discussion and problem- } \\
\text { solving, but most work is } \\
\text { still done alone in individual } \\
\text { workstations Group } \\
\text { members are collocated }\end{array}$ & $\begin{array}{l}\text { Individual workstations } \\
\text { Tables and chairs or lounge- } \\
\text { type furniture located } \\
\text { within easy reach of private } \\
\text { workstations; moveable } \\
\text { screens or partitions } \\
\text { May have white boards, } \\
\text { computer connections }\end{array}$ & $\begin{array}{l}\text { Ability to meet rapidly and } \\
\text { spontaneously } \\
\text { Ability to draw passers by into } \\
\text { the meeting } \\
\text { Flexibility - can rearrange } \\
\text { space as needed }\end{array}$ & $\begin{array}{l}\text { Noise from meetings may } \\
\text { disturb others nearby } \\
\text { Loss of privacy for group } \\
\text { discussions } \\
\text { Usefulness depends on } \\
\text { whether the workers } \\
\text { located near one another } \\
\text { work together on projects }\end{array}$ \\
\hline $\begin{array}{l}\text { Non-territorial, high- } \\
\text { mobility office } \\
\text { Precipitating conditions } \\
\text { unclear; may be most } \\
\text { beneficial when work tasks } \\
\text { clearly need different kinds } \\
\text { of spaces and when work is } \\
\text { largely paperless }\end{array}$ & $\begin{array}{l}\text { Different types of workspaces } \\
\quad \text { (individual, group, } \\
\text { enclosed, open) } \\
\text { No personal, dedicated } \\
\text { individual workspace } \\
\text { Mobile technologies }\end{array}$ & $\begin{array}{l}\text { Efficient space utilization } \\
\text { Ability to work in spaces best } \\
\text { suited to different kinds of } \\
\text { tasks }\end{array}$ & $\begin{array}{l}\text { Difficulties in locating people, } \\
\text { if the workspace is large or } \\
\text { on multiple floors } \\
\text { Difficulties for storing and } \\
\text { accessing paper files } \\
\text { Technology must be } \\
\text { adequate to support high } \\
\text { mobility }\end{array}$ \\
\hline $\begin{array}{l}\text { Radical collocation } \\
\text { project room } \\
\text { High need for interaction to } \\
\text { reduce time to complete } \\
\text { group products; highly } \\
\text { interdependent work and } \\
\text { need to track group } \\
\text { progress on multiple tasks }\end{array}$ & $\begin{array}{l}\text { Enclosed room with large } \\
\text { group work table Individual } \\
\text { computer stations for team } \\
\text { members working } \\
\text { continuously in the space } \\
\text { Multiple telephones plus } \\
\text { telephone conferencing } \\
\text { capability } \\
\text { White boards and tack boards } \\
\text { External spaces for individual, } \\
\text { concentrated work }\end{array}$ & $\begin{array}{l}\text { Easy access to all team } \\
\text { members } \\
\text { Ability to track group and } \\
\text { individual progress through } \\
\text { displayed information } \\
\text { Enhanced ability to answer } \\
\text { questions and deal with } \\
\text { problems or questions as } \\
\text { they arise } \\
\text { Rapid coordination of tasks }\end{array}$ & $\begin{array}{l}\text { May be distracting to work } \\
\text { requiring individual } \\
\text { concentration } \\
\text { Reduced privacy } \\
\text { High internal focus may lead } \\
\text { to loss of interaction with } \\
\text { other organizational } \\
\text { groups }\end{array}$ \\
\hline $\begin{array}{l}\text { Extreme collaboration } \\
\text { project room } \\
\text { High need for interaction to } \\
\text { reduce time to complete } \\
\text { group products; group has } \\
\text { highly interdependent and } \\
\text { parallel tasks; high need for } \\
\text { sophisticated technology } \\
\text { supports and access to } \\
\text { shared databases }\end{array}$ & $\begin{array}{l}\text { Enclosed room with open, } \\
\text { individual workstations (no } \\
\text { visual barriers) } \\
\text { High visual and aural access } \\
\text { High level of technological } \\
\text { supports - performance } \\
\text { modelling and simulation } \\
\text { tools, information } \\
\text { visualization, multiple } \\
\text { interactive graphic displays } \\
\text { Display walls }\end{array}$ & $\begin{array}{l}\text { Easy access to all group } \\
\text { members } \\
\text { Multiple, simultaneous side } \\
\text { bar conversations to share } \\
\text { information rapidly and } \\
\text { solve emergent problems } \\
\text { Rapid coordination (leads to } \\
\text { reduced time to complete } \\
\text { tasks) }\end{array}$ & $\begin{array}{l}\text { Requires training to develop } \\
\text { skills for working in the } \\
\text { environment } \\
\text { Mental fatigue due to high } \\
\text { information and sensory } \\
\text { load } \\
\text { Applies to a limited range of } \\
\text { work contexts (complex, } \\
\text { multidisciplinary science } \\
\text { and engineering projects) }\end{array}$ \\
\hline
\end{tabular}

continuing access to short-term memory or computation suffers from distractions and interruptions (Jones and Morris, 1992; Perlow, 1999; Banbury et al., 2001).

\section{Links between effective individual work and physical space Overview}

Individual work requiring confidentiality or quiet is supported by both spatial features and ambient conditions. Key spatial factors include a high degree of enclosure (Archea, 1977; Pedersen, 1997), low density that provides adequate distance from disruptive noise (Kupritz, 1998; Fried et al., 2001) and distance from high-circulation areas (Backhouse and Drew, 1992).

Many offices also include small, enclosed spaces (focus booths) for concentration and privacy. Although there is no systematic research on the effectiveness of these spaces, evidence from a case study suggests that focus booths and small enclosed rooms have had mixed 
success (Heerwagen et al., 2002). The case study identified several design problems, including poor soundproofing, a lack of connections to local area networks and a lack of mobile technologies to support spontaneous movement between open-plan workstations and small, private spaces.

In addition to spatial features, ambient conditions can aid or inhibit individual work due to effects on attention and concentration. For instance, high temperatures and poor ventilation reduce effectiveness on numerous mental tasks due to drowsiness and reduced effort (Wyon, 1996). In contrast, the ability personally to control temperatures and ventilation at the desk top has beneficial effects on numerous individual work tasks (Kroner et al., 1992; Menzies et al., 1997). Although the exact mechanisms by which personal control works are still unclear, it is likely that having the ability to create personally comfortable environments increases comfort and possibly motivation (Veitch et al., 2003).

Research also shows that window views influence cognitive functioning, especially distant views or views of nature. Benefits include improved concentration (Hartig et al., 1991), stress reduction (Kaplan, 1992) and increased 'cognitive tranquillity' (Clearwater and Coss, 1999). The cognitive and psychological benefits of views may result from the ability to weave minimental breaks into on-going work, thereby restoring attentional capacity and the ability to concentrate (Kaplan, 1995, 2001).

\section{Potential benefits and constraints}

The availability of individual workspaces that aid focused attention and reduce distractions and interruptions has numerous benefits, including increased time on individual tasks (Perlow, 1999), reduced stress (Kaplan, 1992), improved performance on mental tasks (Wyon, 1996), and the ability to maintain one's line of thought and cognitive flow (Csikszentmihalyi, 1990).

As noted above, however, the workplace is rampant with distractions that reduce attention, reduce time for individual work, increase stress and interrupt mental activities.

Combined with demands for attention from multiple sources and increased multitasking, the environment for individual knowledge work suffers from what psychologists call 'cognitive overload syndrome' (Lahlou, 1999; Kirsh, 2000). Overload not only reduces individual work effectiveness, but also it has social implications and can lead to tension with colleagues, a loss of job satisfaction and a strained work relationships (Kirsh, 2000). Cognitive overload also results from the fast pace and stresses of work. As noted above, knowledge work is rife with multitasking, excessive information demands and time pressures. As Kirsh (2000, p. 22) notes:

Our workplaces are supposed to help us cope with these problems. But our tools and resources remain inadequate. We can turn the ringer off on our telephones, we can close our doors, we can auto-filter our e-mail, we can personalize search engines, ask people to honor privacy, and so forth. But blocking out sacred time segments or sealing ourselves off from outside contact and even filtering email is not a serious solution in most organizations. And where it is acceptable, it still leaves unaddressed the overload that arises from multi-tasking, interruption and information overload that we create ourselves in having to design how to manage our desks, files, computers, and different projects.

Kirsh recommends using the environment as a 'cognitive ally' to increase effectiveness and to reduce stress. This requires a better design of individual workspaces as well as reduced noise distractions and interruptions from co-workers. One way to begin, according to Kirsh, is to ask how difficult, or easy, it is to do a task in a particular space and what environmental supports are necessary for successful performance. Consider, for instance, more effective storage of individual documents. Despite the ability to store all documents electronically, many workers still have piles of paper on desks and other available surfaces (Sellen and Harper, 2002). From the perspective of individual work effectiveness, paper has many advantages over electronic documents. It is easier to read, review, edit and annotate.

Lahlou (1999) approached the design of storage devices from a cognitive and behavioural perspective. Using video recording of behaviours as a key methodology, his research team identified more effective ways to store documents, thereby clearing desks of clutter and reducing the demands for attention. The storage technique uses mobile racks that allow the documents to remain at the periphery of attention (and therefore not 'out of sight, out of mind') and to be easily retrievable. The design has open, labelled shelves with the documents in work stacks rather than in file folders in a cabinet. The fact that documents are still in view is important because it enables ideas and thoughts stored in the documents to be made readily available when needed. At the same time, the improved visual organization of space eliminates the clutter of piles in the central field of view competing for attention. It seems like an intuitively obvious solution, yet most filing cabinets are closed, difficult to move and difficult to organize in a manner that makes information retrieval efficient.

\section{Summary}

Table 5 summarizes findings on individual work effectiveness. 
Table 5 Individual work effectiveness

\begin{tabular}{|c|c|c|c|}
\hline Precipitating conditions & $\begin{array}{l}\text { Supporting features and } \\
\text { attributes }\end{array}$ & Key benefits & Problems and constraints \\
\hline $\begin{array}{l}\text { Confidentiality } \\
\text { Time pressures } \\
\text { Complex mental work } \\
\text { Work that could result in } \\
\text { errors when interrupted } \\
\text { Solitary activities: reading, } \\
\text { writing, thinking, } \\
\text { synthesizing information } \\
\text { into individual knowledge } \\
\text { structures }\end{array}$ & $\begin{array}{l}\text { Enclosure (doors and walls) } \\
\text { Distance from noise- } \\
\text { generating sources } \\
\text { High workstation panels } \\
\text { Ambient control } \\
\text { Cognitive aids for memory } \\
\text { and attention }\end{array}$ & $\begin{array}{l}\text { Improved time on task } \\
\text { Improved performance on } \\
\text { mental tasks } \\
\text { Improved ability to } \\
\text { concentrate and maintain } \\
\text { cognitive flow } \\
\text { Reduced stress }\end{array}$ & $\begin{array}{l}\text { Reduced workplace } \\
\text { awareness } \\
\text { Reduced potential for } \\
\text { interactions }\end{array}$ \\
\hline
\end{tabular}

\section{Summary and concluding remarks}

It was noted above that collaborative work is a system of behaviours that includes both social factors (awareness, brief interaction, collaboration) and accommodation of solitary work. There are many ways to support both collaborative behaviours and solitude through the manipulations of spatial layouts, circulation systems, visibility, adjacencies, furnishings and ambient conditions.

However, providing the right level of enclosure, density, privacy and ambient control for effective individual work is often at odds with goals to increase interaction. Private offices, high workstation panels or greater separation of individual workstations make it easier to concentrate but more difficult to see and hear what is going on. Furthermore, long hallways lined with private offices increase distances and reduce foot traffic, thereby reducing the likelihood of spontaneous interactions and quick meetings that are important for maintaining collaborative relationships (Kraut et al., 1990; Serrato, 2000). On the other hand, spaces designed to increase awareness and interaction also increase the potential for interruptions and distractions. This is the central dilemma of collaborative work environments - providing effective support for both interactive and individual work.

The research linking cognition and the environment addresses an important aspect of individual work that is overlooked, i.e. the link between cognitive processing and workstation design. Much of the research cited in this paper focuses on reducing distractions and interruptions from people. In contrast, the cognitive approach considers how to improve the individual workstation by reducing factors that create cognitive and sensory overload, while adding or improving components that aid cognitive processing.

\section{Do we need a 'cognitive cocoon'?}

The problems for individual work effectiveness suggest that the workplace should provide a cocoon-type space that, like the biological entity, has numerous beneficial capabilities: It surrounds, but does not entirely cut off outside stimulation. It has within it necessary support for growth and development. Its design is simple, but the solution is elegant. It provides release when the occupant determines the time is right.

Workplace design is currently moving in the opposite direction. Individual workspaces are becoming smaller, more open and more mobile, with the emphasis on ready connection to information and co-workers, either electronically or face-to-face. Little heed is being paid to using the personal space as a cognitive work ally.

The research discussed in this paper also shows that many collaborative workplaces have met with mixed success. Some are highly successful but others are not. In part, this is due to misapplication of research findings that become popularized, such as Allen and Gerstberger's (1973) work on the non-territorial office for $\mathrm{R} \& \mathrm{D}$ scientists, or research on the link between communication and innovation (Allen, 1977). Findings from such studies are often generalized and then applied to vastly different organizational contexts and work processes. The misapplication of a non-territorial workplace strategy at the advertising firm Chiat-Day, for example, resulted in complaints and disruptive behaviours that made it difficult to carry out work, and forced the organization into a costly decision to abandon the design and revert to a more traditional space in two large offices.

In addition to a lack of fit between work and space, there is a common belief among designers as well as organizational leaders that a high level of interaction and collaboration is a general good, rather than a means to aid particular kinds of work processes and tasks. This may lead to an over emphasis on interaction, raising the potential for communication behaviours to interfere with the ability of individuals to get their work completed.

Unfortunately, resulting problems with distractions and interruptions are treated as a side-effect that can 
be reduced by working at home or by using small, private spaces elsewhere in the office. However, existing research shows that mobility may not be as easy as believed, especially given the continued reliance on paper documents and a lack of a full suite of technologies to support internal mobility (Heerwagen et al., 2002; Sellen and Harper, 2002).

Given the well-documented problems for individual work, why has this raised so little concern? Why has so little attention been given to creating more effective individual spaces? The following three explanations are proposed. The first concerns an attribution bias in human social judgements. In general, people are highly salient features in others' lives and their behaviours tend to stand out against the environmental context in which they occur. This creates difficulties for analysing objectively the person-environment milieu, and it is especially problematic when making judgements about people's performance related behaviours. As observers, people have a strong bias to see others' performance difficulties as attributable to something about them, e.g. they do not try hard enough, they are not motivated. Observers (e.g. managers) tend to ignore factors in the worker's environment that contribute to performance difficulties (Heerwagen et al., 1985).

A second potential explanation concerns the reward structure in organizations. Since rewards are often geared toward individual achievement, workers benefit by behaving 'heroically' and overcoming any obstacles that might get in the way of being effective (Perlow, 1999). Thus, organizations are unlikely to pay attention to dissatisfaction and potential loss of work effectiveness if individuals are willing to work hard to overcome problems. However, there is a risk in not recognizing the problem. Even if workers increase their effort to perform well, there are side-effects that can erode organizational effectiveness over time. Lowered motivation, increased stress, irritability and lowered organizational citizenship efforts may not be obvious at first, but the cumulative effect could take a toll.

A third potential explanation revolves around the difference in perceived risks posed by barriers to collaboration at an organizational level. An organization as a whole might stand to loose more by under- than by over-communicating. As the research by Allen (1977) and others (notably Chachere et al., 2003) has shown, high levels of interaction and communication are linked to innovation and reduced time to complete complex projects. Thus, decision-makers are likely to focus on these high-level benefits and to ignore the potential for lowered individual effectiveness. However, these studies show that high levels of communication and interaction are important for complex work that requires a merger of insights, perspectives and disciplines such as those encountered in scientific research and development. Does the same hold true for other knowledge work disciplines?

\section{Further research needs}

Although there is much research on collaborative behaviours in work environments, there has been little systematic research on the linkages between collaborative behaviour, organizational effectiveness and physical space, for example:

- Full links between spatial features, collaborative behaviours and organizational outcomes. At present, most research addresses parts of the linkage. For instance, links between space and brief interactions have been studied, as have links between interaction and group or organizational benefits. However, few studies other than the pioneering research by Allen (1977) have sought to make the links from space to behaviour to organizational value. Will the linkages continue to hold as different types of knowledge work are assessed? At present, the research focuses on scientific $R \& D$, software development and design.

- Link between collaborative behaviours and positive organizational consequences, such as increases in a sense of community, organizational attachment or positive citizenship behaviours. Do improvements in collaborative behaviours have benefits on these aspects of organizational life?

- Link between collaborative behaviours and collaborative corporate culture. Can changes in the workplace produce changes in collaborative behaviours that, in turn, influence cultural norms and values?

- Identifying the tradeoffs between individual and collaborative work for different contexts. Under what circumstances does collaboration become too costly to the individual - for instance, the time needed to maintain relationships and networks may detract sufficiently from individual accomplishment to make further investments inappropriate. Does this point differ for different kinds of work?

There are many other potential research topics beyond those suggested here. Because of the high organizational interest in collaboration and communication, the authors expect research in this field to be rich and varied in the coming decades.

\section{Acknowledgements}

The authors thank a number of close colleagues who shared their interest in creating workplaces that support human, organizational and environmental 
goals. First, Glen S. Hunter, Jr, Director of Applied Science, Public Buildings Service, and F. Joseph Moravec, Commissioner of Public Buildings, US General Services Administration, are thanked for strong leadership and support. Second, a number of close colleagues who were instrumental in the development of ideas presented are thanked, especially for many stimulating discussions and insights: Azizan Aziz, Carnegie Mellon University; Kevin Kelly, Donald Horn, Francis Mazarella, Jeanne Trelogan, Robert Obenreder, Michael Atkinson and Lois Bennett, GSA; Michael Chapman, US Navy; and Karen Pero, Public Works \& Government Services, Canada. The authors also thank the anonymous reviewers for many helpful comments.

\section{References}

Allen, T.J. (1971) Communications networks in R\&D laboratories. R\&DD Management, 1(1), 14-21.

Allen, T.J. (1977) Managing the Flow of Technology: Technology Transfer and the Dissemination of Technical Information within R\&D Organizations, MIT Press, Cambridge, MA.

Allen, T.J. and Gerstberger, P.J. (1973) A field experiment to improve communications in a product engineering department: the non-territorial office. Human Factors, 15(5), 487-498.

Archea, J. (1977) The place of architectural factors in behavioral theories of privacy. Journal of Social Issues, 33(3), 116-137.

Artman, H. (2000) Team situation assessment and information distribution. Ergonomics, 43(8), 1111-1128.

Backhouse, A. and Drew, P. (1992) The design implications of social interaction in a workplace setting. Environment and Planning B: Planning and Design, 19, 573-584.

Bagnara, S. and Marti, P. (2001) Human work in call centers: a challenge for cognitive ergonomics. Theoretical Issues in Ergonomics, 2(3), 223-237.

Banbury, S.P., Macken, W.J., Tremblay, S. and Jones, D.M. (2001) Auditory distraction and short term memory: phenomena and practical implications. Human Factors, 43(1), 12-29.

Baumeister, R.F. and Leary, M.R. (1995) The need to belong: desire for interpersonal attachments as a fundamental human motivation. Psychological Bulletin, 117(3), 497-529.

Becker, F. and Sims, W. (2001) Offices That Work: Balancing Communication, Flexibility, and Cost. International Workplace Studies Program. Cornell University, Ithaca (available at: http://iwsp.human.cornell.edu).

Belojevic, G., Slepcevic, V. and Jakovlevic, B. (2001) Mental performance in noise: the role of introversion. Journal of Environmental Psychology, 21, 290-213.

Beyerlein, M.M., Freedman, S., McGee, C. and Moran, L. (2003) Beyond Teams: Building the Collaborative Organization. Jossey-Bass/Pfeiffer, San Francisco.

Brager, G., Heerwagen, J., Bauman, F., Huizenga, C., Powell, K., Ruland, A. and Ring, E. (2000) Team Spaces and Collaboration: Links to the Physical Environment. Center for the Built Environment, University of California, Berkeley.

Brill, M., Weidemann, S. and BOSTI Associates (2001) Disproving Widespread Myths About Workplace Design. Kimball International, Jasper, IN.

Brown, J.S. and Duguid, P. (2000) The Social Life of Information. Harvard Business School Press, Boston.

Buckingham, M. and Coffman, C. (1999) First, Break All the Rules: What the World's Greatest Managers Do Differently. Simon \& Schuster, New York.

Chachere, J., Kunz, J. and Levitt, R. (2003) Can You Accelerate Your Project Using Extreme Collaboration? A Model
Based Analysis. Technical Report 154. Center for Integrated Facilities Engineering, Stanford University, Palo Alto.

Carletta, J., Anderson, A.H. and McEwan, R. (2000) The effects of multimedia communication technology on non-collocated teams: a case study. Ergonomics, 43(8), 1237-1251.

Claxton, G. (2000) Hare Brain, Tortoise Mind: How Intelligence Increases When You Think Less. HarperCollins, New York.

Clearwater, Y.A. and Coss, R.G. (1990) Functional esthetics to enhance well-being in isolated and confined settings, in A.A. Harrison, Y.A. Clearwater and C.P. McKay (eds): From Antarctica to Outer Space: Life in Isolation and Confinement. Springer, New York, pp. 331-358.

Csikszentmihalyi, M. (1990) Flow: The Psychology of Optimal Experience. Harper \& Row, New York.

Drucker, P. (1959) Landmarks of Tomorrow. New York, Harper.

Dunbar, R.I.M. (1997) Groups, gossip, and the evolution of language, in A. Schmitt, K. Atzwanger, K. Grammer and K. Schafer (eds): New Aspects of Human Ethology. Plenum, New York, pp. 133-160.

Evans, G.W. and Johnson, D. (2000) Stress and open-office noise. Journal of Applied Psychology, 85(5), 779-783.

Fried, Y., Slowik, L.H., Ben-David, H.A. and Tiegs, R.B. (2001) Exploring the relationship between workspace density and employee attitudinal reaction: an integrative model. Journal of Occupational and Organizational Psychology, 74, 359-372.

Gabarro, J.J. (1987) The development of working relationships, in J.W. Lorsch (ed.): Handbook of Organizational Behavior. Englewood Cliffs, NJ, Prentice-Hall, pp. 172-189.

Gutpa, A.K., Govindarajan, V. and Malhotra, A. (1999) Feedback-seeking behavior within multinational corporations. Strategic Management Journal, 20, 205-222.

Gutwin, C. and Greenberg, S. (2001) A Descriptive Framework of Workspace Awareness for Real Time Groupware. CSCW'01. Kluwer, Dordrecht.

Hansen, M.T. (2002) Knowledge networks: explaining effective knowledge sharing in multiunit companies. Organization Science, 13(3), 232-248.

Hargadon, A.B. (1999) Group cognition and creativity in organizations. Research on Managing Groups and Teams, 2, 137-155.

Hartig, T., Mang, M. and Evans, G. (1991) Restorative effects of natural environment experiences. Environment and Behavior, 23, 3-26.

Heerwagen, J.H., Beach, L.R. and Mitchell, T.R. (1985) Dealing with poor performance: supervisor attributions and the cost of responding. Journal of Applied Social Psychology, 17(7), $638-653$.

Heerwagen, J.H., Hunt, B. and Hunt, L. (2002) Post Occupancy Evaluation of the Region 10 Office of the Future. Office of Applied Research, Public Buildings Service, US General Services Administration, Washington, DC.

Horgen, T.H., Joroff, M.L., Porter, W.L. and Schon, D.A. (1999) Excellence by Design: Transforming Workplace and Work Practice. Wiley, New York.

Hutchins, E. (2002) Cognition in the Wild. MIT Press, Cambridge, MA.

Jones, D.M. and Morris, N. (1992) Irrelevant speech and cognition, in D.M. Jones and A.P. Smith (eds): Handbook of Human Performance, Vol. 1. Academic Press, London, pp. 29-53.

Kaplan, R. (1992) Urban forestry and the workplace, in P.H. Gobster (ed.): Managing Urban and High-use Recreation Settings. General Technical Report NC-163. North Central Forest Experiment Station, USDA Forest Service, Chicago.

Kaplan, S. (1995) The restorative effects of nature: toward an integrative perspective. Journal of Environmental Psychology, 15, 169-182.

Kaplan, S. (2001) Meditation, restoration, and the management of mental fatigue. Environment and Behavior, 33(4), $480-506$. 
Katz, R. and Tushman, M. (1979) Communication patterns, project performance, and task characteristics: an empirical evaluation and integration in an R\&D setting. Organizational Behavior and Human Performance, 23, 139-162.

Katzenbach, J.R. and Smith, D.K. (1999) The Wisdom of Teams. HarperCollins, New York.

Kendon, A. (1990) Conducting Interaction: Patterns of Behavior in Focused Encounters. Cambridge University Press, Cambridge.

Kerr, N.L. and Tindale, R.S. (2004) Group performance and decision making. Annual Review of Psychology, 55, 623-655.

Kirsh, D. (2000) A few thoughts on cognitive overload. Intellectica, 1(30), 19-51.

Kjellberg, A., Landstrom, U., Tesarz, M., Soderbert, L. and Akerlund, E. (1996) The effects of nonphysical noise characteristics, on going task and noise sensitivity on annoyance and distraction due to noise at work. Journal of Environmental Psychology, 16, 123-136.

Kraus, W.A. (1980) Collaboration in Organizations. Human Sciences, New York.

Kraut, R.E., Egido, C. and Galegher, J. (1990) Patterns of contact and communication in scientific research collaboration, in J. Galagher, R.E. Kraut and C. Egido (eds): Intellectual Teamwork. Earlbaum, Hillsdale.

Kroner, W., Stark-Martin, J.A. and Willemain, T. (1992) Using Advanced Office Technology to Increase Productivity. Center for Architectural Research, Rensselaer Polytechnic Institute, Troy.

Kupritz, V.W. (1998) Privacy in the work place: the impact of building design. Journal of Environmental Psychology, 18, $341-356$.

Lahlou, S. (1999) Observing cognitive work in offices, in N.S. Streitz, J. Siegel, V. Hartkoff and S. Konomi (eds): Cooperative Buildings: Integrating Information, Organizations, and Architecture. Proceedings of the 2nd International Workshop, CoBuild'99, Pittsburgh, PA, US, pp. 1-4.

Lawrence, P.R. and Nohria, N. (2002) Driven: How Human Nature Shapes Our Choices. Jossey-Bass, San Francisco.

Marks, G. (2002) Extreme collaboration. Communciations of the ACM, 45(6), 89-93.

McCarrey, M.W., Peterson, L., Edwards, S. and Von Kulmiz, P. (1974) Landscape office attitudes: reflections of perceived degree of control over transactions with the environment. Journal of Applied Psychology, 59(3), 401-403.

McGee, J. (2002) Knowledge work as craft work. McGee's musings (available at: http://www.kellog.new.edu/facl $\mathrm{mcgee} / \mathrm{htm} / \mathrm{blog} /$ stories/2002/03/21).

McGrath, J. (1984) Groups: Interaction and Performance. Prentice-Hall, Englewood Cliffs, NJ.

Menzies, D., Pasztor, J., Nunes, F., Leduc, J. and Chan, C.-H. (1997) Effect of a new ventilation system on health and well-being of office workers. Archives of Environmental Health, 52(5), 360-368.

Moreland, R.L. and Argote, L. (2003) Transactive memory in dynamic organizations, in R. Peterson and E. Mannix (eds): Understanding the Dynamic Organization. Earlbaum, Mahwah, NJ, pp. 135-142.

Organ, D.W. and Ryan, K. (1995) A meta-analytic review of attitudinal and dispositional predictors of organizational citizenship behavior. Personnel Psychology, 48, 775-802.

Pashler, H., Johnson, J.C. and Ruthruff, E. (2001) Attention and performance. Annual Review of Psychology, 52, 629-651.

Pedersen, D.M. (1997) Psychological functions of privacy. Journal of Environmental Psychology, 17, 147-156.

Penn, A., Desyllas, J. and Vaughan, I. (1999) The space of innovation. Environment and Planning B: Planning and Design, 26, 193-218.

Perlow, L.A. (1999) The time famine: toward a sociology of work time. Administrative Science Quarterly, 44, 57-81.

Rashid, M., Kampschroer, K., Wineman, J. and Zimring, C. (2004) Face-to-Face Interaction in Office Setting: What You Know About It May Not be Always True. Technical
Report. Georgia Institute of Technology, College of Architecture, Atlanta, GA.

Reder, S. and Schwab, R.G. (1990) The temporal structure of cooperative activity, in CSCW'90 Proceedings. New York, ACM Press, pp. 303-320.

Rizzo, A., Marti, P., Veneziano, V. and Bagnara, S. (1999) Engaging with organizational memory, in J. Bliss, P. Light and R. Saljo (eds): Learning Sites: Social and Technological Contexts for Learning. Oxford, Elsevier, pp. 110-119.

Rognin, L. and Bannon, L. (2001) Sharing Information. Unpublished report, Interactive Design Center, University of Limerick (available at: http://www.ul.ie/ idc/library/ papersreports/LaurenceRognin).

Sellen, A.J. and Harper, R.H.R. (2002) The Myth of the Paperless Office. MIT Press, Cambridge, MA.

Serrato, M.G. (2002) Building based communication research (available at: http://www.tradelineinc.com).

Sims, W.R., Joroff, M. and Becker, F. (1998) Teamspace Strategies: Creating and Managing Environments to Support High Performance Teamwork. IDRC Foundation, Atlanta.

Suchman, L. (2000) Making a case: 'knowledge' and 'routine' work in document production, in P. Luff, J. Hindmarsh and C. Heath (eds): Workplace Studies: Recovering Work Practice and Informing System Design. Cambridge University Press, Cambridge, pp. 29-45.

Sundstrom, E., Town, J.P., Brown, D.W., Forman, A. and McGee, C. (1982) Physical enclosure, type of job, and privacy in the office. Environment and Behavior, 14(5), 543-559.

Sutton, R.I. and Hargadon, A. (1996) Brainstorming groups in context: effectiveness of a product design firm. Administrative Science Ouarterly, 41, 685-718.

Szilagyi, A.D. and Holland, W.E. (1980) Changes in social density: relationships with functional interaction and perceptions of job characteristics, role stress, and work satisfaction. Journal of Applied Psychology, 65(1), 28-53.

Tafalla, R. and Evans, G.W. (1992) Noise, physiology and human performance: the potential role of effort. Journal of Occupational and Health Psychology, 2, 148-155.

Teasley, S., Covi, L., Krishnan, M.S. and Olson, J.S. (2000) How does radical collocation help a team succeed?, in Proceedings of CSCW'00, 2-6 December 2000, Philadelphia, PA, US.

Tsai, W. (2002) Social structure of 'coopetition' within a multiunit organization: coordination, competition and intraorganizational knowledge sharing. Organization Science, 13(2), 179-190.

Tsai, W. and Ghoshal, S. (1998) Social capital and value creation: the role of infirm networks. Academy of Management Journal, 41(4), 464-476.

Veitch, J., Boyce, P., Myer, M. and Hunter, C. (2003) Lighting Quality and Office Work. Final Report on the Light Right Consortium Study of Lighting Quality, Laboratory Phase. Report 404141. Pacific Northwest National Laboratory, Richland, WA.

Weiser, M. and Brown, J.S. (1996) The coming age of calm technology (available at: www.ubiq.com/ypertext/weiser/acmfuture2endnote.htm).

Wilson, D.S., Wilczynski, C., Wells, A. and Weiser, L. (2000) Group and other aspects of language as group-level adaptations, in C. Heyes and L. Huber (eds): The Evolution of Cognition. MIT Press, Cambridge, MA, pp. 347-366.

Wyon, D.P. (1996) Indoor environmental effects on productivity, in Proceedings of IAQ'96, 'Paths to Better Building Environments', 6-8 October, Baltimore, MD, USA.

Zalesny, M., Salas, E. and Prince, C. (1995) Conceptual and measurement issues in coordination: implications for team behavior and performance. Research in Personnel and Human Resources Management, 13, 81-115.

Zijlstra, F.R.H., Roe, R.A., Leonora, A.B. and Krediet, I. (1999) Temporal factors in mental work: effects of interrupted activities. Journal of Occupational and Organizational Psychology, 72, 163-185. 